
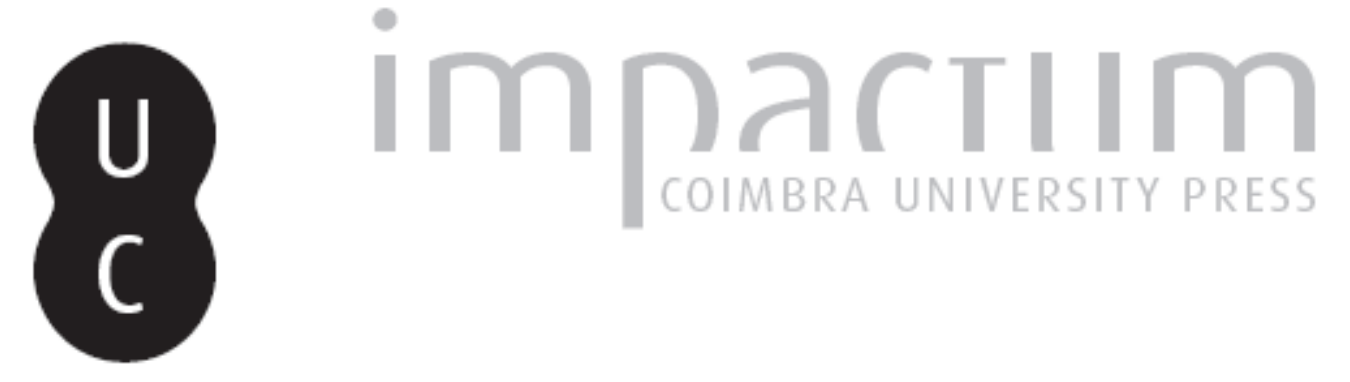

\title{
A inflexão quotidiana do serviço público de media
}

\section{Autor(es): Mateus, Samuel}

Publicado por: Imprensa da Universidade de Coimbra

URL persistente:

URI:http://hdl.handle.net/10316.2/39190

DOI:

DOI:http//dx.doi.org/10.14195/2183-6019_2_8

Accessed : $\quad$ 26-Apr-2023 13:05:27

A navegação consulta e descarregamento dos títulos inseridos nas Bibliotecas Digitais UC Digitalis, UC Pombalina e UC Impactum, pressupõem a aceitação plena e sem reservas dos Termos e Condições de Uso destas Bibliotecas Digitais, disponíveis em https://digitalis.uc.pt/pt-pt/termos.

Conforme exposto nos referidos Termos e Condições de Uso, o descarregamento de títulos de acesso restrito requer uma licença válida de autorização devendo o utilizador aceder ao(s) documento(s) a partir de um endereço de IP da instituição detentora da supramencionada licença.

Ao utilizador é apenas permitido o descarregamento para uso pessoal, pelo que o emprego do(s) título(s) descarregado(s) para outro fim, designadamente comercial, carece de autorização do respetivo autor ou editor da obra.

Na medida em que todas as obras da UC Digitalis se encontram protegidas pelo Código do Direito de Autor e Direitos Conexos e demais legislação aplicável, toda a cópia, parcial ou total, deste documento, nos casos em que é legalmente admitida, deverá conter ou fazer-se acompanhar por este aviso. 
revista de comunicação,

jornalismo e espaço público

2

Periodicidade

Semestral

Imprensa da Universidade de Coimbra Coimbra University Press

\section{mediapolis}

tema

os desafios dos media

de serviço público

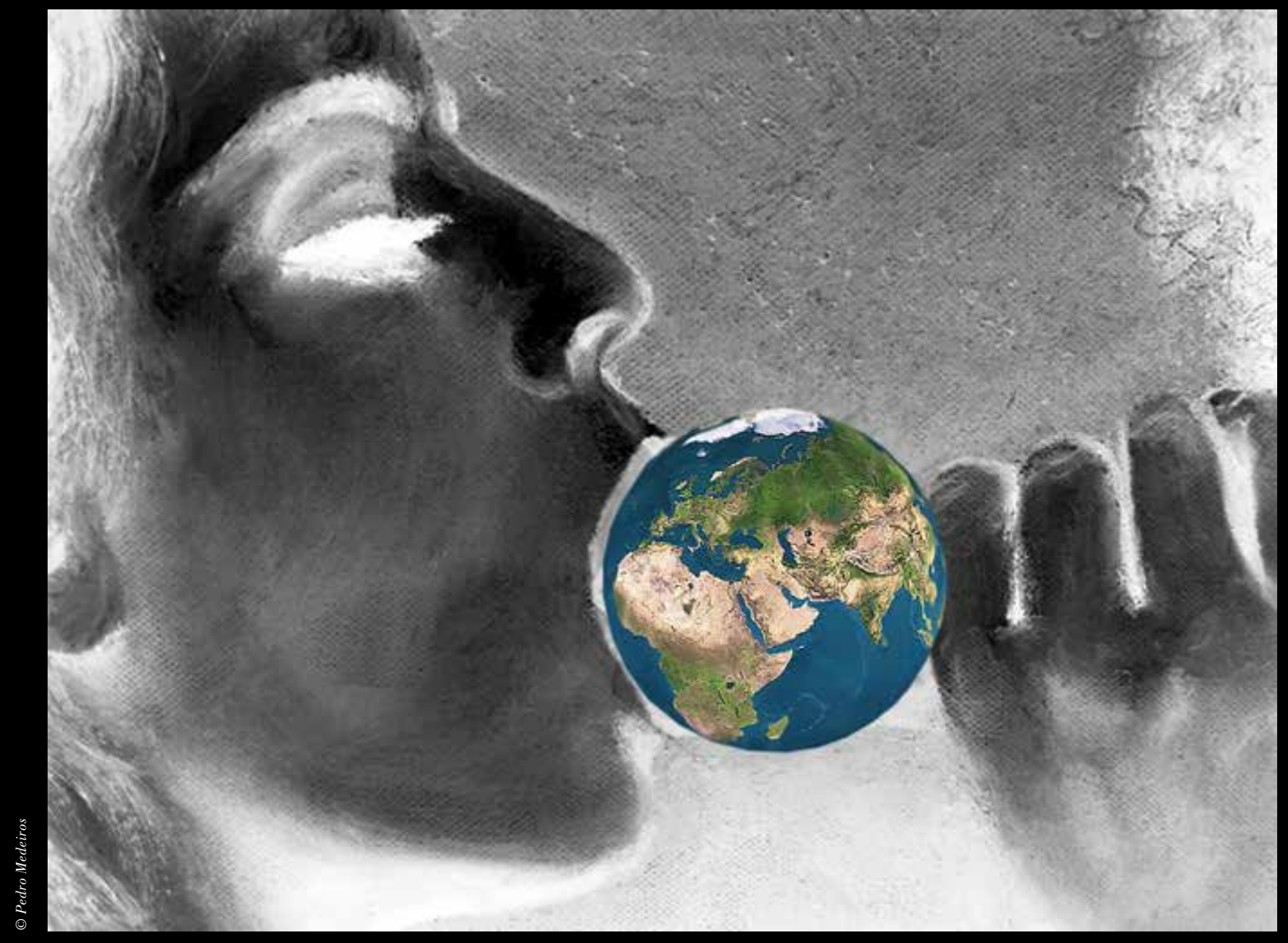




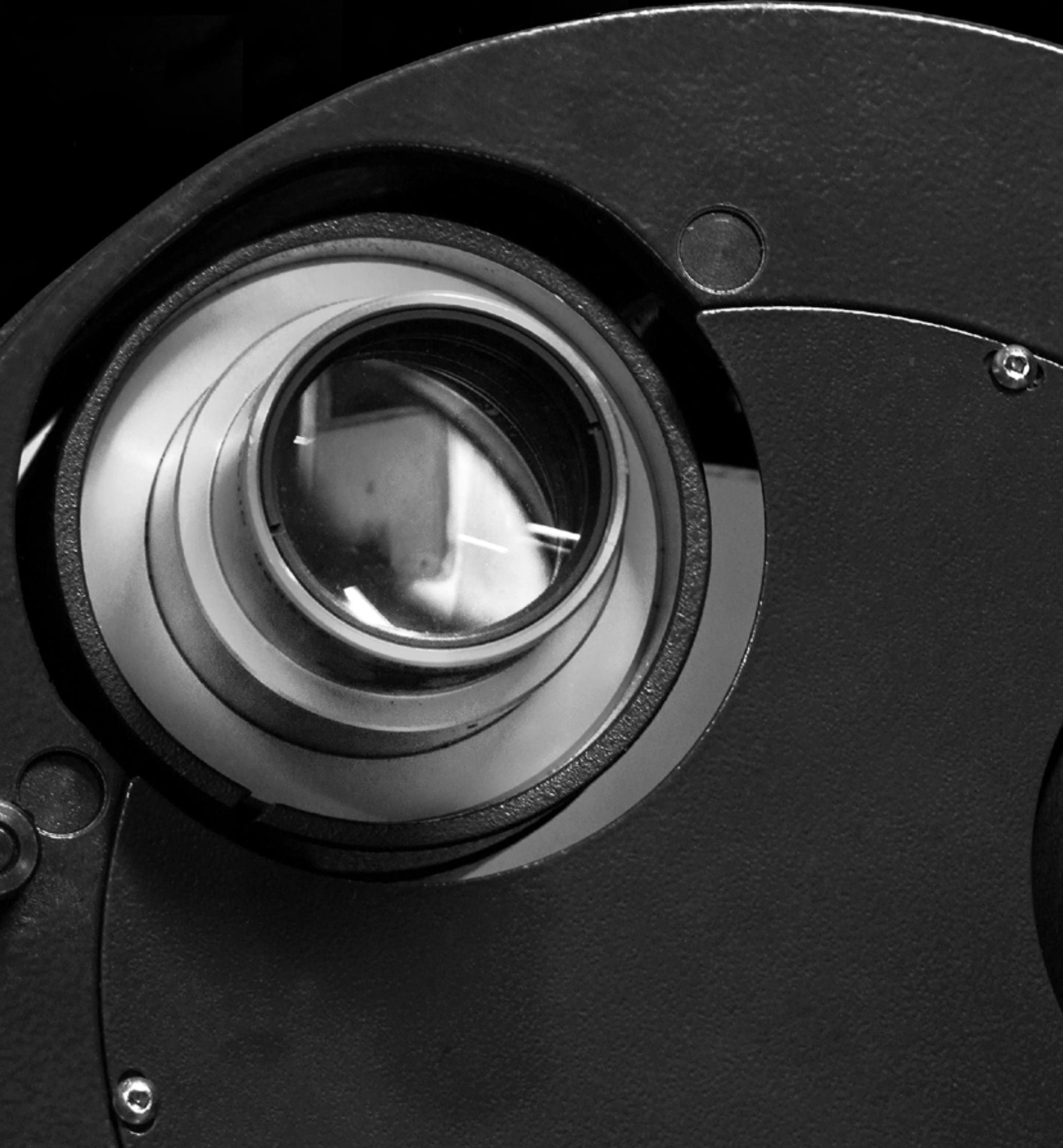




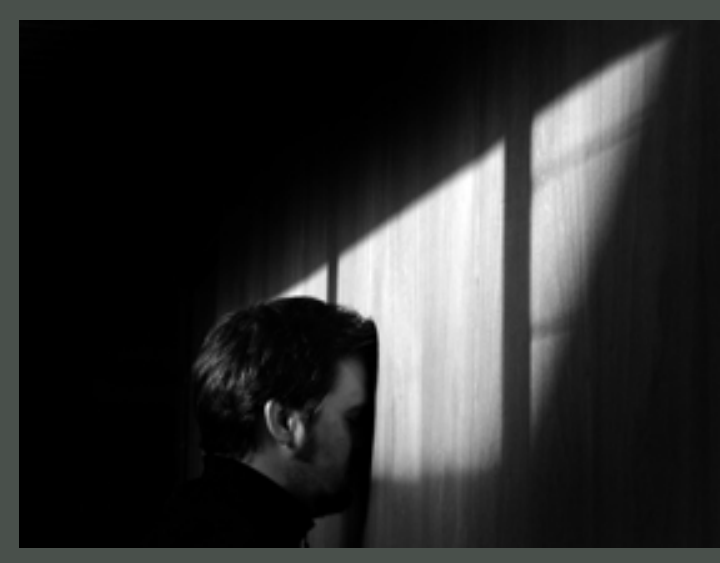




\section{Samuel Mateus}

Bolseiro Pós-Doutoramento FCT

e Investigador do CECL/UNL

sammateu@gmail.com

\section{A inflexão quotidiana do serviço público de media}

The daily inflection of the public service media

http://dx.doi.org/10.14195/2183-6019_2_8

Resumo:

Historicamente, o Serviço Público de $M e$ dia tem sido associado a duas dimensões interrelacionadas: a dimensão político-democrática e a dimensão educativa. Por um lado, ele subentende um papel preponderante de formação de uma opinião pública esclarecida como parte essencial do processo político. E, ao contribuir para o fortalecimento democrático, enquanto instância simultaneamente separada do Estado e do Mercado, o Serviço Público de Media está igualmente a desempenhar um papel educacional. Para além da informação e do entretenimento, ele possui a obrigação de garantir e preservar elevados padrões de qualidade na sua programação que correspondam ao modelo moral das sociedades.

Uma terceira dimensão igualmente importante é a dimensão integradora do Serviço Público de Media, ou se quisermos, a relação que se estabelece entre sociedade e publicidade na sua articulação com os dispositivos tecnológicos de mediação simbólica.

Este artigo procura refletir sobre a dimensão convergente do Serviço Público de Media através do destaque concedido à sociabilidade mundana, quer ao nível das temáticas, quer ao nível da organização da própria programação. O que está em causa nesta enfatização da mundanidade é que o interesse geral parece agora moldado por uma motivação em ver representado no Serviço Público de Media a própria vida quotidiana das próprias pessoas a quem se dirige. É um discurso não apenas voltado para a objetividade e atualidade informativa, como também para a subjetividade e autenticidade dos próprios indivíduos.

Palavras-chave: Serviço público de media, publicidade, quotidiano, autenticidade, subjetividade.

\section{Abstract:}

The Public Service Broadcasting has historically been associated with two interrelated dimensions: a political and democratic dimension, and an educational dimension. It has an important role for forming an enlightened public opinion as an essential part of the political process. While contributing to the strengthening of democracy (apart from State and Market), the Public Service Broadcasting is also playing an educational role. In addition to information and entertainment, its duty is to protect and uphold high standards of quality in its programming that correspond to the moral model of societies.
A third equally important dimension is the social integration dimension of Public Service Broadcasting and the relationship between society and publicity, and their interaction with Media.

This paper seeks to ponder on the convergent dimension of Public Service Broadcasting highlighting its everyday sociability, both in terms of the topics, and in terms of its structure. What is important in this everydayness is that the general interest now seems framed by a motivation to see represented in the Public Service Media the daily lives of the very people to whom it is addressed. It is a discourse not only facing the objectivity and information, as well as to the subjectivity and authenticity of the individuals.

Keywords: Public service broadcasting, publicity, everyday life, suthenticity, subjectivity. 


\section{Introdução}

Um dos traços marcantes do funcionamento do Serviço Público de $M e$ dia é a sua - ainda que maior ou menor - associação ao Estado. No início do séc. XX, e tomando como modelo a $\mathrm{Bri}$ tish Broadcasting Corporation (BBC), o Serviço Público de Comunicação foi assumido como um operador sob controlo estatal a quem era reconhecido o estatuto de instituição do domínio público (Sondergaard, 1999: 22). O Serviço Público de Media não pode ser completamente dissociado do controlo estatal, tanto em termos políticos, como em termos tecnológicos. Afinal, cabe ao Estado a gestão pública de um bem escasso como é o caso do espectro radioelétrico; além de que tem como missão, não apenas garantir que uma multiplicidade de bens e serviços sejam assegurados aos cidadãos, como também deve assumir, ele próprio, o fornecimento de serviços fundamentais (de acordo com os princípios do Estado-Providência).

O Serviço Público de Media, enquanto utilidade pública e bem coletivo em prol do interesse coletivo, reveste-se de uma dimensão democrática incontornável face ao seu enorme potencial de criação de uma cidadania esclarecida e informada. Permite a um vasto conjunto de pessoas tomar conhecimento e obter informação relevante que ajudem a formar a sua própria compreensão dos acontecimentos. A ideia de Serviço Público de Media incarna, então, a constituição de uma Opinião Pública elucidada e razoável como elemento fundamental do processo político das sociedades democráticas. Ele baseia-se no pressuposto de que o fomento da autonomia de decisão dos grupos sociais prevenirá uma sociedade burocrática e centralizada, encontrando na participação dos cidadãos a sua maior valia (Masuda, 1980: 81). Pinto (2005: 43) considera que uma das condições de democratização e qualificação do serviço público é precisamente pensá-lo e realizá-lo em harmonia com o sentir geral da sociedade e propõe que o serviço público o seja de uma cidadania e para a cidadania.

Paralelamente ao papel político-democrático do Serviço Público de Comunicação, encontramos nele um papel concomitante: o educativo. Significa que, com vista a ser um elemento unificador (política, linguística e culturalmente), o Serviço Público de Media procura manter um distinto padrão moral que eleve a erudição e conduza o gosto. Deste modo, muitos programas de televisão e rádio dignificam as tradições nacionais e regionais (Portugal em Direto, RTP1) histórias e lendas (Horizontes da Memória, RTP2; Histórias assim mesmo, Antena 1), educam a expressão linguística (Cuidado com a Língua, RTPl) ou utilizam a televisão como meio de difusão do conhecimento (Universidade Aberta, RTP2). O Serviço Público de Media adquiriria a sua qualidade propriamente publicitária enquanto vetor cultural e ético das sociedades, funcionando de acordo com uma orientação baseada na pedagogia política, cultural e social da sua programação.

Uma terceira dimensão, tão importante quanto a político-democrática e a educativa - mas a que tem sido dedicada menos atenção -, é aquela que tem a ver com a integração social e a reprodução de padrões de sociabilidade que encontramos na vida de todos os dias. Muitos talk-shows (Portugal no Coração, RTP1) dedicam-se 


\section{O Serviço}

\section{Público de Media}

significa um

espaço simbólico

de congregação

e de unificação

das sociedades principalmente a reencenar as pequenas conversas do quotidiano, as incertezas e curiosidades ou o diálogo ameno como forma de atenuar o efeito de solidão de muitas das pessoas que diariamente assistem a esses programas. A dimensão propriamente social do Serviço Público de Comunicação inscreve-se na sua missão ecuménica, isto é, a de fornecer um espaço de mediação simbólica onde a transmissão pública de acontecimentos (desportivos, políticos ou culturais) de elevada relevância coletiva funciona como uma espécie de cimento aglutinador (Scannell, 1989: 14).

O Serviço Público de Media, e em especial nesta segunda década do séc. XXI, parece procurar ser popular e universal, evitando que se transforme num gueto cultural e social. Há, assim, uma abertura em direção ao exterior, às pessoas, à vida e ao trivial. Ele concentra-se, sobretudo, em ser um serviço que opera o próprio princípio de publicidade: é nessa medida que o Serviço Público de Media interpela não apenas o cidadão, mas o indivíduo comum, a pessoa vulgar, o público indiscriminado, tornando os acontecimentos acessíveis a todos.
É, pois, na medida em que articula e agiliza o processo publicitário que o Serviço Público de Media significa um espaço simbólico de congregação e de unificação das sociedades. O espectador, ouvinte ou leitor não é apenas considerado enquanto consumidor ou audiência, mas também enquanto membro de uma sociedade que converge para os Media.

Podem ser distinguidos dois tipos de convergência publicitária: a convergência dos olhares em que a atenção pública se volta para determinado acontecimento - a convergência implicada pela televisão cerimonial (Dayan \& Katz, 1999); e a convergência pública do indivíduo comum sobre os Media. É este indivíduo vulgar, presente no chamado "Grande Público" (Wolton, 1994), nessa heterogeneidade e pluralidade social, que aflora no ecrã televisivo ou nas ondas hertzianas da rádio dos Media Públicos.

O Serviço Público de Media opera ambos os tipos de convergência: a convergência da atenção da sociedade sobre determinados eventos de relevância pública incontornável; e, ao mesmo tempo, opera a convergência da sociedade sobre si própria, sobre os 
próprios indivíduos que a constituem. A dimensão englobante do Serviço Público de Media manifesta-se, na contemporaneidade, pela sua incidência sobre o indivíduo anónimo. Agora são os próprios espectadores a serem os objetos privilegiados de atenção do Serviço Público.

O presente artigo procura aprofundar esta dimensão convergente e interpeladora do Serviço Público de Media. Na atualidade - é argumentado - observa-se uma tendência em espelhar a realidade. Contudo, a representação da sociedade não é operada apenas em termos objetivos e factuais; é sobretudo operada de modo subjetivo, através dos olhos dos próprios indivíduos que a experienciam. Recorrendo a exemplos retirados do Serviço Público de Televisão e de Rádio, serão analisadas três dimensões deste processo: "quotidianização", autenticidade e subjetividade.

\section{Serviço "Público": \\ diversidade e universalidade}

O Serviço Público de Media distingue-se, hoje, pela forma como interpela os indivíduos, se lhes dirige, e os coloca como instâncias enunciativas fazendo-os pivots do acesso à experiência social. É um aparelho "público" que ausculta em discurso direto, na primeira pessoa e em primeira mão, um serviço público que se centra na universalidade de todos sem obliterar as particularidades de cada um. Eis o Serviço Público como plataforma coletiva acessível a qualquer um.

Entre Serviço Público de Media e indivíduos a distância esboroa-se. Já não é o intervalo de um "eu" e "tu", mas a coincidência de um "nós" enquanto expressão convergente. Face à pedagogia do papel educativo dos Media Públicos, interpõe-se agora um papel “amigável”, um companheirismo mediático baseado numa relação de convivialidade que acompanha o espectador/ ouvinte ao longo do dia de acordo com os ritmos da vida quotidiana. Pense-se, por exemplo, na distribuição estratégica de alguns programas de rádio pelo dia de modo a que coincidam com as horas de maior tráfego automóvel.

O Serviço Público de Media marca encontro com a própria sociedade, simula-lhe os ritmos, repete os ciclos horários, emite em sincronia com a hora do almoço e do jantar. Ocorrem, assim, interações ritualizadas (Lopes, 2005: 83), refletindo os espaços exteriores (Praça da Alegria, RTPl), por vezes mesmo invadindo o Espaço Público (Aqui Portugal, RTP1; Brasileiros pelo Mundo, TV Brasil Internacional), incorporando os hábitos rotineiros como o café matinal (Quem Tu Pensas que $\left.E s^{1}, \mathrm{RPT} 1\right)$, ou mesmo constituindo-se como réplicas de sociabilidade (Clube da Amizade ${ }^{2}$, RDP Internacional).

A saliência da trivialidade bem como o protagonismo concedido ao lado mais humano, emocional e íntimo das pessoas não constituem uma disrupção do normal funcionamento do Serviço Público. A ênfase na dimensão social e publicitária face à

1 Na descrição do programa feita pela RTP pode-se ler: "Programa factual em registo de documentário que procura responder à pergunta - sabe realmente quem é? - através da descoberta da árvore genealógica e de histórias reais sobre os antepassados do convidado de cada programa".

2 A RDP caracteriza-o do seguinte modo: "O convívio de sábado. Programa aberto à participação dos ouvintes; lança temas para discussão, relata experiências pessoais e associativas, confronta diferentes modos de vida e serve de ponte entre as diferentes comunidades". 
dimensão político-democrática e educativa corresponde até a uma perfeita interpretação do princípio de mutabilidade consignado no Relatório do Grupo de Trabalho para a Definição do Conceito de Serviço Público de Comunicação Social (Duque et al., 2011) e que impõe ao Serviço Público de Comunicação uma constante adaptação e apropriação à sociedade. Se o interesse público se encontra em devir, então, cabe ao Serviço Público de Media reconhecer esses interesses e acomodá-los nas suas práticas. O recente advento do indivíduo comum na televisão e na rádio públicas inscreve-se nesse processo. Como lembra o relatório da UNESCO sobre "Serviço Público":

No serviço público de media, a informação não se restringe a boletins noticiosos ou programas de assuntos públicos; estende-se a todos os programas que permitam os cidadãos tomar conhecimento de diferentes tópicos de interesse e todos aqueles programas de interesse geral que tratam assuntos de interesse prático ou mundano (...). É através deste tipo de programação que o serviço público se aproxima das necessidades específicas das pessoas (UNESCO, 2001: 18).

Estamos, pois, a enfatizar, a palavra publicitária do serviço de Media sublinhando as ligações afetivas que estabelece com a sociedade, ligações essas tão mais importantes quanto mais se regista a tendência de fragmentação e individualismo. Um Serviço Público de Media que se invente em termos de programas de interesse geral é um Serviço Público capaz de se adaptar à realidade social, económica e política colocando-se ao serviço da comunidade que serve.

\section{Em direção ao quotidiano}

A dimensão sociológica e convergente do Serviço Público de Media pode ser mais bem compreendida enquanto viragem rumo a uma enfatização da vida quotidiana do indivíduo comum. A atenção prestada à banalidade e ao desenrolar das rotinas diárias por muitos dos programas que compõem o Serviço Público de
Comunicação indicam uma tentativa de levar aqueles que assistem (os espectadores e os ouvintes) a identificarem-se com os que aí participam.

O Serviço Público de Media apresenta duas relações com o quotidiano. Por um lado, uma relação de emulação, reproduzindo o quotidiano no cenário dos seus programas. Ele procura instituir uma cópia perfeita, não apenas das preocupações do indivíduo comum, mas também aspetos do dia-a-dia. Um exemplo paradigmático no caso do Serviço Público português de Televisão é o programa Praça da Alegria (RTP1). Emitido ininterruptamente desde 1995, o talk-show simula em estúdio um espaço público (uma praça) e uma esplanada. A plateia integra o cenário em volta da "praça" não sendo, portanto, mera observadora. Nos anos 1990, o apresentador deambulava de mesa em mesa, por entre os indivíduos anónimos da plateia, consoante a colocação do entrevistado. A emulação do quotidiano por intermédio da reprodução do espaço público atingia, nessa época, laivos de perfeita sincronia com uma qualquer e trivial esplanada. Havia empregados de mesa a servir café e água, não apenas aos convidados do programa como a 
toda a plateia. O chão imitava a calçada portuguesa e, a rodear a "praça", largas arcadas donde pendiam grandes candeeiros completavam o cenário inspirado numa qualquer paisagem urbana.

Por outro lado, o Serviço Público de Media contemporâneo parece recriar o próprio quotidiano, trazendo tópicos da vida prática para a cena pública. Praça da Alegria serve-nos, de novo, como exemplo pelo modo como integra aspetos da vida mundana na sua organização temática. Até inícios do séc. XXI, a rubrica de culinária era indispensável no programa e continua esporadicamente a aparecer. Além disso, temas do foro privado relacionados com a vida prática são recorrentes. Recentemente, ensinava-se ao público feminino como colocar um soutien corretamente. Mas o que sobressai em Praça da Alegria da RTPl - mas também noutros programas como Bom para Todos da TV Brasil, se quisermos estender este atributo do Serviço Público de Media a outros países - são as transformações ao nível da enunciação que se aproximam da coloquialidade informal, adquirindo mesmo, por vezes, um tom intimista e confidente.
$\mathrm{O}$ que se nota nestes programas de Serviço Público é que o seu estilo de comunicação não é o do discurso público, da comunicação política ou da deliberação; o seu estilo discursivo recorda-nos, pelo contrário, um estilo aparentado com a conversa íntima, mundana e familiar, assente nos contextos da vida diária. Aliás, Scannell (1991: 9) atribui o desenvolvimento da rádio e da televisão a este estilo de comunicação, semelhante aos contextos interativos da vida de todos os dias. Aproveitando este padrão discursivo de feição coloquial e quotidiana, os diferentes Serviços Públicos de Media têm assegurado na sua programação - e de acordo com graus diversos - uma dimensão banal que aproxima os indivíduos e onde eles se reconhecem (modos de vestir, hábitos de comportamento, expressões linguísticas frequentemente associadas a gírias, etc.).

O Serviço Público está, deste modo, não apenas a difundir comportamentos quotidianos como também utiliza um registo informal para se dirigir aos cidadãos. Isto é, ele não apenas incorpora pessoas banais anónimas e comuns, como repete padrões de discurso e de
Mais do que

observar, o

indivíduo parece

hoje desejar

participar

(ex: apps interativas

da RTP e da TVI)

- mesmo que à

distância -

nas próprias

emissões e assistir

a eventos genuínos 
interação que reiteram a dimensão trivial das suas emissões.

Estamos, pois, perante dois níveis de análise: i) o modo como o indivíduo comum e as preocupações quotidianas se apossam das emissões do Serviço Público; ii) o modo como o próprio Serviço Público de Media replica uma certa sociabilidade e dimensão conversacional associada à vida quotidiana através da temática mundana e do estilo de apresentação (Bonner, 2003: 44).

Arguimos uma quotidianização do Serviço Público, tendo citado dois talk-shows. Esta tendência, porém, repercute-se noutros géneros televisivos. Por exemplo, no género informativo. Portugueses no Mundo ${ }^{3}$, emitido diariamente pela Antena 1 , espelha as realidades sociais, profissionais e afetivas enfrentadas pelos emigrantes portugueses. Aí se conta, na primeira pessoa, o dia-a-dia do cidadão português no estrangeiro, seja em Macau ou em Goa, seja em Boston ou Amesterdão. Como estudou, onde trabalhou, que

3 Com apresentação de Alice Vilaça, o programa surge no site da RTP como "uma conversa com os portugueses espalhados pelos quatro cantos do mundo". dificuldades enfrenta na adaptação à cultura. Este tipo de programação, presente quer na Rádio, quer na Televisão (Portugueses pelo Mundo, RTP1) não apenas do Serviço Público de Media português, como também brasileiro (Brasileiros pelo Mundo, TV Brasil Internacional), transpira o quotidiano.

No caso do programa televisivo, os indivíduos são acompanhados pela equipa de reportagem desde que se levantam, passando pelo emprego ou pelo almoço com os colegas num restaurante famoso da cidade, até às saídas noturnas pelos bairros típicos com os amigos locais. O espetador imerge, assim, na mundanidade, tal como vivida e experienciada pelo emigrante. Constata a vida quotidiana de uma cidade estrangeira tornando-se, não tanto um observador, mas sobretudo uma testemunha: senta-se à mesa do café, entra no laboratório, percorre as ruas de uma cidade mundial presenciando à distância o bulício de que o emigrante todos os dias toma parte. Na descrição de Portugueses pelo Mundo, no site oficial da RTP, é flagrante a insistência sobre a mundanidade:

\begin{abstract}
Ao mesmo tempo, haverá lugar para que os entrevistados mostrem, na primeira pessoa, os costumes do lugar visitado, em muitos casos curiosos ou ousados, alguns inimagináveis para a mente ocidental ou, simplesmente, portuguesa. Partilhar um passeio por um mercado cheio de gente e produtos; praticar um ritual pagão rodeado de pessoas pouco amigáveis; assistir a um casamento onde os noivos não se conhecem um ao outro; provar e comer um estranho prato típico com ingredientes que nunca pensámos que poderíamos vir a comer, são apenas algumas das múltiplas e variadas situações que irão suceder-se em cada uma das emissões. Assim, os nossos protagonistas serão sempre os melhores guias para conhecer a vida quotidiana do lugar onde estamos.
\end{abstract}

A inflexão registada pelo Serviço Público de Media acompanha, pois, esta tendência de dar visibilidade ao quotidiano trivial, tanto nas pessoas que aparecem representadas, como na própria expressão dessa representação, como veremos de seguida. 


\section{Em direção à autenticidade}

A participação dos indivíduos no Serviço Público de Comunicação não é apenas garantida pela emergência do quotidiano nos programas de rádio e televisão; é também, como afirmámos, marcada pela sua própria emergência enquanto sujeitos.

Abraçando uma tendência presente na rádio e televisão mainstream (privadas e de pendor comercial) (Jost, 2003: 62), o Serviço Público tem, em graus diversos de acordo com especificidades impostas pelo seu próprio modelo de financiamento, também ele, preferido a palavra do indivíduo anónimo, da pessoa comum e vulgar. Ele associa, de forma cada vez mais estreita, o espectador à conceção, desenvolvimento e orientação dos seus programas. $\mathrm{O}$ maior exemplo serão os programas televisivos de realidade, os quais constituem o culminar do envolvimento do público na dramaturgia televisiva (Mehl, 2006: 169).

Esta preferência - que encontramos, por exemplo, em Chef's Academy ${ }^{4}$

4 Descrito de acordo com o slogan: "Aprenda a cozinhar na maior escola de cozinha do país. Este é um formato de cozinha que, além da componente de concurso, pretende ensinar
(RTP1, 2013) - é, talvez, justificada por uma busca de autenticidade exigida pelo cidadão. Mais do que observar, o indivíduo parece hoje desejar participar (ex: apps interativas da RTP e da TVI) - mesmo que à distância - nas próprias emissões e assistir a eventos genuínos. Porém, este imperativo de autenticidade não responde apenas a uma exigência por parte dos cidadãos que assistem, ele é também desejado pelos próprios operadores do Serviço Público de Media, na medida em que, ao conceder a palavra ao indivíduo comum, isto é, ao secularizar o acesso aos media, eles espelham, de forma direta, a própria sociedade para a qual trabalham.

Programas do Serviço Público de Televisão como Inesquecível (RTP Memória), em Portugal, Toute une Histoire (France 2), em França, ou Vivo en Argentina (Tv Publica), na Argentina, ilustram - com as devidas diferenças o lugar concedido à palavra autêntica, às histórias contadas na primeira pessoa do singular, à experiência vivida. $\mathrm{O}$ indivíduo comum desliza subtilmente

verdadeiramente a cozinha (...). Esta é a verdadeira oportunidade de mudar de vida e de profissão". da posição de espetador para a de ator, tornando-se duplamente agente: agente de uma sociedade em movimento e simultaneamente agente de uma televisão que se aproxima progressivamente da mundanidade. $\mathrm{O}$ indivíduo comum é testemunha da realidade e delator dessa realidade, descreve-a, relata-a, torna-a partilhada. $\mathrm{O}$ que está em causa nestes programas é a "exibição do relacional" (Mehl, 2006: 172), é a contemplação da autenticidade dos indivíduos através das relações interpessoais, dos acontecimentos e das suas próprias experiências. $\mathrm{O}$ discurso sobre violência doméstica passa a ter um rosto; o pesadelo do desemprego passa a ter uma voz; ou a rejeição profissional passa a ser enunciada por alguém que a viveu por dentro.

A importância que a televisão assume na encenação pública contemporânea impede que se reduza o espaço público a um fórum de ideias ou a um palco de debates. A dimensão de comparência, da visibilidade, torna-se central em qualquer processo de coletivização de uma ideia, de uma proposta ou de uma ação (Mehl, 2006: 185). 
A autenticidade é um aspeto fundamental de programas como $\mathrm{Babel}^{5}$ (TVE) ou Começar de Novo ${ }^{6}$ (Antena 1). Neles, as gentes aparecem com dignidade própria, surgem imbuídas do seu discurso e dissertam, com mais ou menos emoção, sobre os desafios que ultrapassaram. Por exemplo, Começar de Novo implica a Rádio Pública portuguesa (Antena 1) na missão de dar voz aos testemunhos pessoais das pessoas que viveram nas antigas colónias portuguesas, antes e após a Revolução dos Cravos. É o relato emocionado de quem chegou à metrópole vindo do Portugal Ultramarino e teve justamente de começar de novo. Aí ouvimos as vivências, contadas muitas vezes com profundas saudades, de um tempo em que a rádio suplantava a televisão.

5 "Babel en TVE es la revista de la diversidad de TVE. Una mirada plural y cómplice a un fenómeno social, la inmigración, que día a día contribuye de manera crucial a conformar la España del siglo Xxi. Es una ventana abierta a la vida cotidiana española que muestra cómo viven aquí los inmigrantes; su trabajo, sus formas de ocio, su cultura".

6 "O regresso a 1975/76. A chegada a Portugal em discurso direto. Testemunhos de quem saiu das ex-colónias para «Começar de Novo" ".
Por conseguinte, o Serviço Público de Media tem dado oportunidades para a publicização da autobiografia, isto é, para o retrato de uma época feito pelas gentes que a viveram. Este mesmo objetivo integra o horizonte de Retratos $^{7}$ (RTPl), série documental onde diferentes personalidades, num registo intimista e confessional, testemunham os acontecimentos mais marcantes de uma dada época, a partir precisamente das suas próprias expectativas e da sua perspetiva. Ocorre, assim, com a publicização autobiográfica, um deslocamento das fronteiras da vida privada.

Muitas vezes é esta busca da autenticidade que impele o privado a tornar-se público e onde a vida familiar é compartilhada no e pelo Serviço Público de Media. Referimo-nos particularmente a uma rúbrica de Praça da Alegria (RTP1, 2003) onde semanalmente casais vinham revelar a sua intimidade sob pretexto

7 Segundo o site oficial do programa, “«Retratos» é uma série documental de cariz parcialmente autobiográfico. Pretende-se mostrar como de facto é uma determinada personalidade, o que ela pensa da sua própria vida, e como justifica a sua intervenção pessoal nos principais acontecimentos que viveu". da comemoração das bodas de prata ou de ouro. Era toda a família da pessoa entrevistada que vinha ao estúdio como gesto de homenagem perante o patriarca ou matriarca. Se é verdade que o tema familiar desde sempre esteve presente na Televisão Pública (novelas, boletins informativos, séries de ficção), não é menos verdade que esse mesmo tema tende agora a ser acompanhado do ponto de vista de pessoas anónimas, as quais acedem ao palco televisivo, para fazer partilhar a sua própria ideia de família.

Em suma, a autenticidade implica, em muitos casos do atual Serviço Público de Media, o recurso à experiência vivida ou à história autobiográfica. Ao fazê-lo, arrasta consigo novas configurações de como as categorias de privado e público convivem na Rádio e Televisão contemporâneas.

\section{Em direção à subjetividade}

O Serviço Público de Comunicação, de forma global, apresenta outra tendência na sua programação relacionada com a quotidianização e 
o trabalho de autenticidade: o dispositivo de personalização.

Enquanto num dispositivo impessoal, as representações sociais são abordadas de forma abstrata, factual e analítica, num dispositivo de personalização a realidade social é compreendida a partir da própria perspetiva do sujeito (Sennett, 1992: 193). Construídas em volta do sentimento e da comoção, as representações dependem de um indivíduo "em carne e osso". A sociedade é descrita pelos olhos de um "eu” através das relações pessoais que empreende com outros sujeitos. O que conta na personalização é a manifestação de uma subjetividade e da sua "psicologia", à medida que se elabora em relações intersubjetivas.

Esta dimensão pessoal, que facilmente se transforma numa invocação subjetiva, não é obviamente recente. Porém, no séc. XXI, adquiriu um maior destaque no conjunto da programação dos Media Públicos, os quais apresentam exemplos deste dispositivo de personalização centrado sobre a enunciação subjetiva do indivíduo. A importância maior desta subjetividade tem a ver com as consequências da sua presença no Serviço Público de Comunicação: o pessoal, o subjetivo e o relacional não integram somente a esfera privada, como entram hoje no domínio das paixões públicas, isto é, entram no espaço de publicidade das sociedades ocidentais. É toda uma outra maneira de comunicar que se erige: em vez da neutralidade, a motivação pessoal; em vez da dedução lógica, a intuição; em vez do geral, o particular e situado. As representações veiculadas por alguns dos programas apoiam-se em contextos práticos, fundados nas vivências do indivíduo comum, preferindo o discurso vulgar ao discurso profissional do especialista.

$\mathrm{O}$ que se nos depara em programas como Comment ça va Bien (France 2, 2013) ou Nada a Esconder ${ }^{8}$ (RTPl,

\footnotetext{
8 Eis a descrição do programa no site da RTP: «Nada a Esconder» é um programa de entretenimento que procura revelar o lado humano do mundo empresarial (...). Mas «Nada a Esconder» não se limita a contar as histórias de sucesso do ponto de vista dos próprios. Cada programa oferece ao seu protagonista a possibilidade de analisar o seu êxito pessoal a partir do olhar daqueles que o conhecem melhor, tanto no âmbito profissional como pessoal. Quais as características que melhor o definem? O que faz dele uma pessoa tão especial? Em que é que se revela a sua capacidade de liderança?".
}

2013) é o olhar subjetivo, são os afetos que deixam de ser incógnitos para se personalizarem em olhares, gestos ou lágrimas. As Televisões do Serviço Público, sem deixarem de privilegiar a palavra, fazem-se hoje lugares confessionais onde as subjetividades emergem em conversas íntimas de tom confidente. Nada a Esconder, por exemplo, busca o indivíduo por detrás do líder, a pessoa por detrás do empresário, o pai ou mãe de família que se esconde sob a capa de gestor de sucesso. Procura que sejam os próprios a contar a sua história de vida, fazendo sobressair o lado humano ocultado pelo empreendedorismo. A descrição do programa é clara: "Na companhia de Sílvia Alberto, o protagonista (...) conversará com a apresentadora sobre si próprio, sobre a imagem que tem de si e a que lhe é devolvida por aqueles que trabalham e convivem com ele diariamente".

Um programa semelhante mas de pendor ainda mais subjetivo é Quem é que tu pensas que és? ${ }^{9}$ (RTP1, 2013).

9 Caracterizado como um "Programa factual em registo de documentário que procura responder à pergunta - sabes realmente quem é? - Através da descoberta da árvore genealógica e de histórias reais sobre os antepassados do convidado de cada programa. 
Personalidades de perfil mediático empreendem uma jornada pessoal de descoberta das suas origens. Investigando a sua ascendência, partem em busca de familiares que nunca conheceram ou de quem perderam o contacto. Na página da RTP está escrito sobre o programa:

Em cada episódio, uma celebridade diferente irá encetar uma intensa pesquisa sobre as suas origens e história familiar. Após a análise da árvore genealógica, seguem-se encontros profundamente emocionais e, aos poucos, serão revelados acontecimentos incrivelmente inspiradores. São histórias de heroísmo, amor, traição, intriga e, por vezes tragédia. À medida que cada celebridade é surpreendida com a descoberta de novos e inesperados familiares, o telespectador será encaminhado para uma arrebatadora viagem através da nossa história.

Os convidados são celebridades das mais variadas áreas da sociedade que acompanhamos, descobrindo a sua história e a dos seus antepassados ao mesmo tempo em que conhecemos e caracterizamos a época em que viveram e o nosso próprio passado".
Aqui o

\section{entretenimento não}

visa apenas fazer

a ocupação do

ócio mas, também,

$$
\text { a replicação }
$$

de padrões de

sociabilidade

sem esquecer o

património cultural

das sociedades
O que o programa faz, no fundo, é percorrer diversos marcos da história recente de Portugal. Fá-lo, todavia, recorrendo a um dispositivo enunciativo baseado na personalização, onde as origens familiares do indivíduo são o pretexto para acompanharmos, de forma emotiva, o desenvolvimento da sociedade portuguesa. Pelos olhos da personalidade, o espectador revive alguns momentos da história social dos dois últimos séculos: a emigração dos avós, a mudança de país ainda criança ou o crescimento no seio de famílias desavindas, etc.

O que é interessante é o paralelismo que o programa do Serviço Público português de Televisão faz entre a ancestralidade da personalidade convidada e a ancestralidade da história coletiva dos portugueses. É como se, por intermédio das raízes e origens do convidado, Quem é que tu Pensas que És indagasse as próprias origens da sociedade portuguesa num curioso exercício que faz coincidir indivíduo e sociedade, singular e coletivo, histórias e História, Serviço Público de Media e Sociedade. 


\section{Conclusão}

Concentrando-nos especialmente sobre o caso português, mas sem deixar de referir outros países, procurámos refletir sobre a dimensão integradora do Serviço Público de Comunicação. A par da dimensão político-democrática e da dimensão educativa, a dimensão sociológica sublinha práticas de inclusão do indivíduo comum no discurso de televisão e rádio. Estas práticas de inclusão assumem uma feição convergente num duplo sentido: convergência enquanto publicidade, enquanto reunião da atenção coletiva; e convergência enquanto emergência do indivíduo vulgar e da mundanidade na Televisão e Rádio Públicas. $\mathrm{O}$ que está em causa nessa dupla convergência continua a ser o horizonte comunitário e coletivo das sociedades. Todavia, esse plano comum distingue-se do trabalho político-democrático e educativo e recorre a três exercícios principais: o do quotidiano, a da autenticidade e o da subjetividade do indivíduo.

Estes três exercícios repetem-se nos media privados. Pode-se inclusivamente falar, como o faz Bonner (2003), numa televisão do vulgar (ordinary television) ou, na expressão de Jost (2003) numa televisão do quotidiano (télévision $d u$ quotidien). Mas o que tentámos foi salientar o carácter distinto com que o Serviço Público de Media articula essas três categorias de acordo com um princípio de sociabilidade (Clube da Amizade, RDP internacional) que busca inspiração nos ritmos quotidianos (Praça da Alegria, RTP1). Essa articulação distinta reside, pois, em trabalhar a identificação coletiva (Portugueses no Mundo, Antena 1), a herança cultural de um país e a história nacional (Quem tu pensas que és, RTPl) através de uma perspetiva mais humilde centrada em torno das ideias de autenticidade e subjetividade. Não estamos já perante uma identidade coletiva enfática, clamada com orgulho sóbrio, mas uma que se constrói de olhar em olhar, de individualidade em individualidade, de quotidiano em quotidiano.

A sensibilização e educação de uma sociedade (duas das mais fortes matrizes do Serviço Público de Media) desaguam, na atualidade, nessa matriz (por vezes reprimida, outras vezes completamente assumida) de entretenimento. Todavia, aqui o entretenimento não visa apenas fazer a ocupação do ócio mas, também, a replicação de padrões de sociabilidade sem esquecer o património cultural das sociedades.

Assim, o conceito de "público" dentro da expressão "Serviço Público de Media" sofre uma importante ampliação: não apenas "Público" num sentido relacionado com a propriedade detida pelo Estado, mas igualmente "público" no sentido em que se opera a partilha simbólica das sociedades. "Público" no seu caráter mais universal e acessível. A inflexão quotidiana, ao enfatizar a mundanidade, mas também a autenticidade e a subjetividade de indivíduos comuns, procede à operacionalização desta ampliação publicitária do Serviço Público de $M e$ dia. Serviço público porque congregação, porque convergência mediática do indivíduo anónimo, serviço público porque representa um exercício de reunião coletiva (sendo, como sabemos, a televisão e rádio dois dos mais abrangentes e inclusivos Media ${ }^{10}$ ).

10 Com efeito, embora ambos requeiram um certo grau de literacia, esse grau é menos exigente do que a literacia da Internet, por exemplo, onde é exigido um conhecimento técnico mínimo para utilização do hardware informático. 
Daí a réplica do quotidiano e de autenticidade, mas igualmente de subjetividade. Daí a relevância social e a originalidade da paisagem contemporânea da Televisão e Rádio Públicas em que os cidadãos são eles próprios atores desse Serviço Público de Media.

\section{Bibliografia}

Bonner, F. (2003). Ordinary Television. London: Sage.

Dayan, D. \& Katz, E. (1999). A história em direto - Os acontecimentos mediáticos na televisão. Coimbra: Minerva Coimbra.

Duque, J., Cristovão, A., Torres, E., Lopes, F., Cabral, F., Amaral, J., Fernandes, J., Damásio, M., Cabral, M., \& Franco, M. (2011). Relatório do grupo de trabalho para a definição do conceito de serviço público de comunicação social. Consultado a 10 novembro de 2013, Disponível em http://static.publico.pt/docs/media/ relatorioGTCS_141111.pdf.

Fidalgo, J. (2005). De que se fala quando se fala em Serviço Público de Televisão?. In M. Pinto, (Coord.), televisão e cidadania - contributos para o debate sobre o serviço público(pp. 23-40). Porto: Campo das Letras.

Jost, F. (2003). La Télévision du Quotidien - entre réalité et fiction. Bruxelas: Éditions De Boek Université.

Mehl, D. (2006). A vida privada pública. In J.C. Abrantes (Org.), Televisão: Das audiências aos públicos (pp. 169-186). Lisboa: Livros Horizonte.

Lopes, F. (2005). Os conteúdos do serviço público de televisão. Pistas para a elaboração de uma grelha de programação. In M. Pinto, (Coord.). Televisão e cidadania - contributos para o debate sobre o serviço público (pp. 81-114). Porto: Campo das Letras.

Pinto, M. (2005). Pensar e projetar o serviço público com a participação do público. In M. Pinto, (Coord.). Televisão e Cidadania - Contributos para o debate sobre o serviço público (pp. 41-60). Porto: Campo das Letras.

Pinto, M. (coord.) (2005a). Televisão e cidadania - contributos para o debate sobre o serviço público. Porto: Campo das Letras.
Raboy, M. (Ed.) (1996). Public Broadcasting to the 21st Century. London: Jonh Libbey Media.

Scannell, P. (1989). Public service broadcasting: History of a concept. In A. Goodwin, \& G. Whannel, (Eds), Understanding Television, (pp. 11-27). London: Routledge.

Scannell, P. (Ed.) (1991). Broadcast Talk. London: Sage

Sennett, R. (1992). The fall of public man. New York and London: Norton \& Company.

Wolton, D. (1994). Elogio do grande público. Porto: Edições Asa.

Wolton, D. (1999). Pensar a comunicação. Lisboa: Difel.

UNESCO (2001). Public broadcasting: Why? How? Conseil mondial de la radiotélévision. Acedido a 10 de novembro de 2011. Disponível em http://unesdoc.unesco.org/images/0012/001240/124058eo.pdf . 